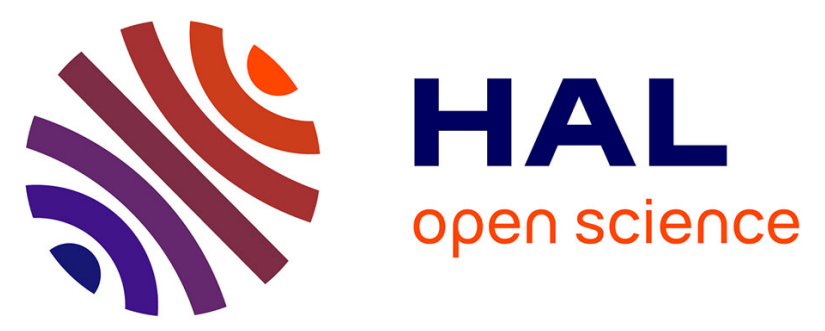

\title{
Towards Data-and-Innovation Driven Sustainable and Productive Agriculture: BIO-AGRI-WATCH as a Use Case Study
}

Asanee Kawtrakul, Hutchatai Chanlekha, Kitsana Waiyamai, Thanapat Kangkachit, Laurent d'Orazio, Dimitris Kotzinos, Dominique Laurent, Nicolas

Spyratos

\section{To cite this version:}

Asanee Kawtrakul, Hutchatai Chanlekha, Kitsana Waiyamai, Thanapat Kangkachit, Laurent d'Orazio, et al.. Towards Data-and-Innovation Driven Sustainable and Productive Agriculture: BIOAGRI-WATCH as a Use Case Study. Workshop on Smart Farming, Precision Agriculture, and Supply Chain (SmartFarm@BigData), Dec 2021, Virtuelle, France. hal-03522308

\section{HAL Id: hal-03522308 https://hal.science/hal-03522308}

Submitted on 12 Jan 2022

HAL is a multi-disciplinary open access archive for the deposit and dissemination of scientific research documents, whether they are published or not. The documents may come from teaching and research institutions in France or abroad, or from public or private research centers.
L'archive ouverte pluridisciplinaire HAL, est destinée au dépôt et à la diffusion de documents scientifiques de niveau recherche, publiés ou non, émanant des établissements d'enseignement et de recherche français ou étrangers, des laboratoires publics ou privés. 


\section{Towards Data-and-Innovation Driven Sustainable and Productive Agriculture: BIO-AGRI-WATCH as a Use Case Study}

\author{
Asanee Kawtraku
Kasetsart Univ. \\ Bangkok, Thailand \\ ak@ku.ac.th \\ Dimitris Kotzinos \\ CY Univ., ETIS, ENSEA, CNRS \\ Cergy-Pontoise, France \\ dimitrios.kotzinos@u-cergy.fr
}

\author{
Kasetsart Univ. \\ Bangkok, Thailand \\ hutchatai.c@ku.ac.th
}

\author{
Kitsana Waiyama \\ Kasetsart Univ. \\ Bangkok, Thailand \\ fengknw@ku.ac.th
}

\author{
Dominique Laurent \\ CY Univ., ETIS, ENSEA, CNRS \\ Cergy-Pontoise, France \\ dominique.laurent@u-cergy.fr
}

\author{
Thanapat Kangkachit \\ Dhurakij Pundit Univ. \\ Bangkok, Thailand
}

thanapat.kan@dpu.ac.th laurent.dorazio@univ-rennes1.fr

\author{
Nicolas Spyratos \\ Univ. Paris-South, LISN, CNRS \\ Orsay, France \\ nicolas.spyratos@lri.fr
}

\begin{abstract}
In this article we introduce a Data and Knowledge Integration Model and a Collaborative Platform for fact-oriented Agricultural Biodiversity Management that is inspired by the conservation and sustainable use of biodiversity within agricultural landscapes, which is essential for the future of agriculture and food security. We demonstrate and validate our proposal in a realistic case study that was carried out with stakeholders from educational institutes including several government agencies from five Ministries, i.e. Ministry of Agricultural and Cooperative, Ministry of Natural Resources and Environment, Ministry of Public Health, Ministry of Commerce and Ministry of Higher Education, Science, Research and Innovation. Key challenges are how to make data inter-operation across these agencies when re-engineering the existing information system and how to make trustworthy platform for data collecting, integrating and sharing, especially, how to keep these agencies engaged throughout the project. The resulting Syntax-Semantic-Organizational Interoperability model was proposed to provide a candidate best practice for engineering data and knowledge integration through a community-shared and reusable Data Reference Model. The resulting Data Governance Implementation across government agencies, by using BIO-AGRI-WATCH as a case study, has significant consequences regarding communication and engagement with stakeholders and dedicated team for increasing their trust in digital data sharing platform.

Index Terms-Agricultural Biodiversity, Trustworthy Information Sharing Platform, Data-Knowledge Driven Precision Farming, Inter-operability Framework, Community-driven Data Governance Implementation
\end{abstract}

\section{INTRODUCTION}

As the world population continues to grow while climate change in the future will make negative impact upon food production, preserving the food security and food sustainability is one of the most important priorities across all levels of government and make the huge challenges in many parts of the world. However, the needed acceleration in productivity growth is obstructed by the high-input, resource-intensive farming systems, which have caused massive deforestation, water scarcities, soil depletion, pollutants, waste and high levels of greenhouse gas emissions, and by climate change which has caused degradation of natural resources, loss of biodiversity and the spread of trans-boundary pests and diseases of plants and animals. These challenges need innovative systems that protect and restore the natural resources such as biodiversity management, while increasing agricultural productivity which provides humans with food security and raw materials for goods and shelter, Chemical active substance for medicines, and materials for biofuel.

Big data are reshaping the world of agriculture helped by the development of innovations in information technology, for examples, sensors, drones, and robotics, AI and virtual and augmented reality, as well as data generation and analytics enabled by remote sensing, and geographic information systems. In this article we propose a platform for trustworthy information sharing and integrating across government agencies. This platform is capable of both intervening in and monitoring various stages of farming process in order to use the related data to make decisions on precision agriculture such as optimal use of fertilizer, water, and pesticides/biocides in heterogeneous field situation, and also conserving biodiversity, which is an important part of ensuring our food sustainability.

Since farmers or growers are not familiar with the biodiversity domain and technological aspects of information systems, a way to provide them with the necessary information is a challenging problem. Moreover, the stakeholders such as strategic planners, entrepreneurs, researchers and actors require heterogeneous data including spatial data for managing trade off and synergies between two sectors: agriculture and biodiversity [2] and across sustainability dimension. Therefore, two of the major challenges are the integration and extraction of these data and their transmission to agricultural biodiversity management actors. The other challenges are how to make data inter-operational when re-engineering the existing information 
system, and how to make the platform trustworthy for data collecting, integrating and sharing with the data owners' engagement.

The pivotal role of our data integration model is to enable syntactic-semantic-organizational inter-operability in multiinformation systems and multi-data sources across domain and agencies owning the data. At present, the platform has been implemented by using BIO-AGRI-WATCH as a use case study for data sharing across several sectors under five ministries. Those are Ministry of Agricultural and Cooperatives, Ministry of Natural Resources and Environment, Ministry of Public Health, Ministry of Commerce and Ministry of Higher Education, Science, Research and Innovation. We also proposed community-driven data governance implementation for data quality management, which is a very important factor for bigdata readiness preparation.

The remainder of the article is organized as follows: Section 2 discusses background and lessons learnt from the related works. Section 3 indicates the challenges and solutions in conserving biodiversity for sustainable agriculture through the proposed platform and inter-operability framework. Implementation results and data governance mechanisms are given in Section 4. Finally, concluding remarks and perspectives for future work are presented in Section V.

\section{BACKGROUND AND RATIONALE}

For agriculture, the productivity indicator is Total Factor Productivity (TFP), which reflects the efficiency with which producers combine inputs to make outputs. However, productivity improvements have not only driven considerable growth in agricultural production, but also a better use of natural resources, resulting in sustainability in preserving available land, water, and biodiversity resources, and respond to climate change. To meet these challenges and respond to opportunities, the sector of agriculture merging with biodiversity will need to embrace innovative approaches to improve productivity and encompasses managing natural resources to ensure their longterm viability and reducing the negative environmental impacts of agriculture production, such as pollutants and waste, which can damage the natural assets. With data-knowledge driven planning, resources optimization and restoration solving, we can reduce the pressure of biological resources depletion.

\section{A. Productive Agriculture and Precision Farming}

Soil and crop parameters are spatially variable in a field. In these conditions spatially uniform rate crop input applications cause increased environmental impact and crop input waste. The key point of precision farming, then, is optimization [11]. By using digital techniques for farm management, such as aerial imagery, sensors, and sophisticated local weather forecasts, agricultural production processes can be monitored and optimized. Together with knowledge applied to farm management through life cycle, it can provide context-aware problem solving, such as personalized fertilizer recommendation, area-based disease prevention. For example, instead of applying equal amount of fertilizer over an entire field, precision agriculture involves measuring the within-field soil variations and adapting the fertilizer strategy accordingly. This leads to economic benefits and to quantify the environmental impacts.

\section{B. Agricultural Biodiversity for Sustainable Use}

Since biodiversity is the origin of the agriculture, i.e, the variety of crops and food, conserving biodiversity for its sustainable use and biodiversity in agricultural landscapes are both essential for food security, nutrition and livelihoods. Agricultural ecosystems that are rich in biodiversity arising from the utilization of genetic resources, provide a diversity of foods that can be used to increase food security and improve nutrient contents, which vary significantly between varieties. For examples:

- Different varieties of rice vary in their protein content from 5 to $14 \%$; and in different banana varieties, the provitamin A content ranges from less than 1 to more than $8,500 \mu \mathrm{g} / 100 \mathrm{~g}$ [10].

- A characteristic of the major crop and livestock species upon which human society depends, has been their ability to adapt and thrive in a wide range of environmental conditions. In recent years, farmers across $50 \%$ of Thailand also struggle with drought and flood. To address these problems, farmers also need help in crop planning with varieties that resist to flood or drought, smart-climate crop management, and crop rotation, that would give farmers greater control in solving their problems.

- Genetic traits such as tolerance to flood, high temperature, drought and water-logging, resistance to particular diseases, pests and parasites will be invaluable resources for enabling future breeding and adaptation.

C. Lessons learned from RICE-DURIAN WATCH and Thailand Biodiversity Information Facility Platform Development $(T H-B I F)$

RICE-DURIAN WATCH are case studies for applying digital techniques and knowledge to solve the problem of crop planning and disease prevention. We also learned the experiences from developing an information facility platform, called TH-BIF, aimed to biodiversity conservation, protection and restoration.

1) Rice Watch Model: Data and Knowledge driven Crop Management: RICE WATCH [1] was a three-year project (2011-2013) supported by the Agriculture Research Development Agency, which aimed to develop a methodology and cloud platform consisting of two main tasks:

- Integrating heterogeneous data stored across government agencies in various and dispersed sources, with different formats and details of information.

- Building rule bases from several websites, which could offer valuable knowledge sufficiently relevant to support decision making together with the local level's data. The knowledge from websites were totally unstructured, containing natural language texts. 

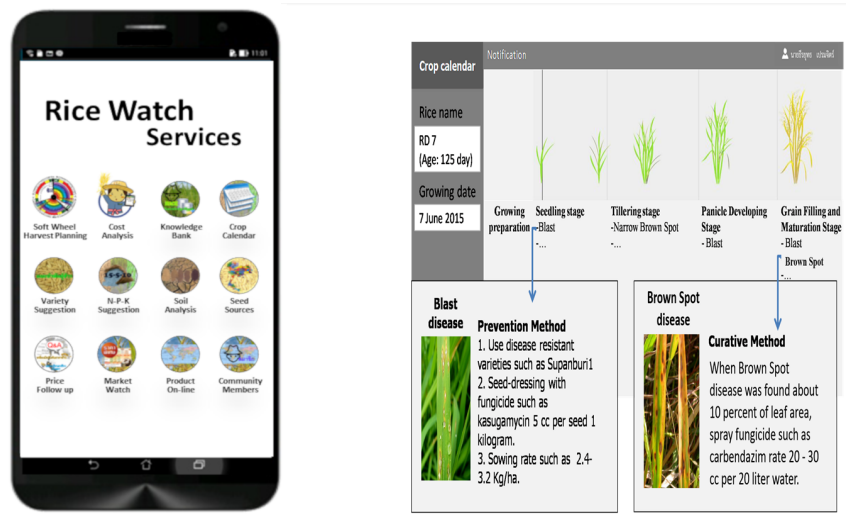

Fig. 1. The service offering from RICE WATCH project

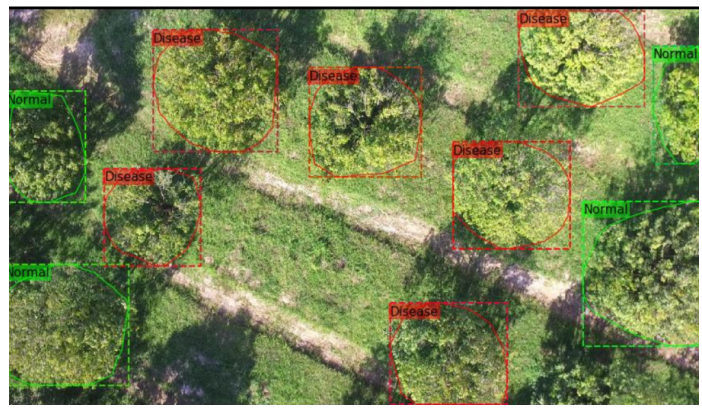

Fig. 2. A Sample of images detecting the difference between disease and normal durian trees

RICE-WATCH provided smallholder farmers with several services through www.ricewatch.org (see Fig. 1), aiming to assist them regarding crop planning [5], disease diagnosis and suggestion for disease prevention or curation, rice fertilizing suggestion, and rice variety suggestions [4], including a context-aware service for early warning [6].

The service innovation development not only aimed to notify "What happens," which relies upon intensive sensing of environmental conditions of the crop, but it also supports the advice delivery of "How to do" that relied on both the heterogeneous data and practical knowledge that enable farmers to achieve greater efficiency and effectiveness in fieldlevel crop management.

With service offering shown in Fig. 1, it would help a farmer to apply actions effectively according to the crop calendar; i.e., the optimal use of pesticides and nutrients in heterogeneous field situations that affect crop quality and reduce risk. Even Rice Watch aimed to help farmers making decisions on critical issues, especially cost and risk reduction such as losses due to pests and environmental factors. However, Rice Watch did not address the issue of how to utilize biodiversity diversity for precision farming while keeping intention about the losses of bio-ecosystem.

2) Durian Watch: Technology-driven Disease Identification: When plants and crops are affected by pests it affects the agricultural productivity. This results in significant yield losses globally. Thus, effective monitoring and accurate detection of plant disease are crucial to ensure stable and reliable production. Plant leaf disease is a symptom that is a visible effect on the plant such as change of the leaf color or shape. In a traditional way, farmers observe the plants with naked eye for detection of disease. Apart from its time-consuming, high-cost and inaccuracy, this method also relies on manual inspection of disease symptoms in a small area by trained farmers or experts.

Recently, advances in unmanned aerial vehicles (UAVs) mounted with hyperspectral image sensors have the potential to address these issues with low cost and high efficiency. Durian Watch was designed and developed an application which helps farmers in automatically detecting plant leaf diseases from bird-eyes view images captured by drone.

This work proposes a deep convolutional neural network (CNN) based approach for automated plant leaf disease detection using bird-eyes view images captured by drone. In the data collection step, sample $2 \mathrm{k}$-resolution videos with 4 minutes length are taken from durian farms in Chantaburi, eastern province of Thailand [8]. These sample videos are converted into images of around 600 disease durian trees, 1,500 normal durian trees and 850 mangosteen trees which almost farmers usually plant them with durian trees. In the data-preprocessing step, we mask those images and then split them into training, validation and testing data sets. In addition, data augmentation process is also applied to produce more images with various brightness and contrast. Based on training 


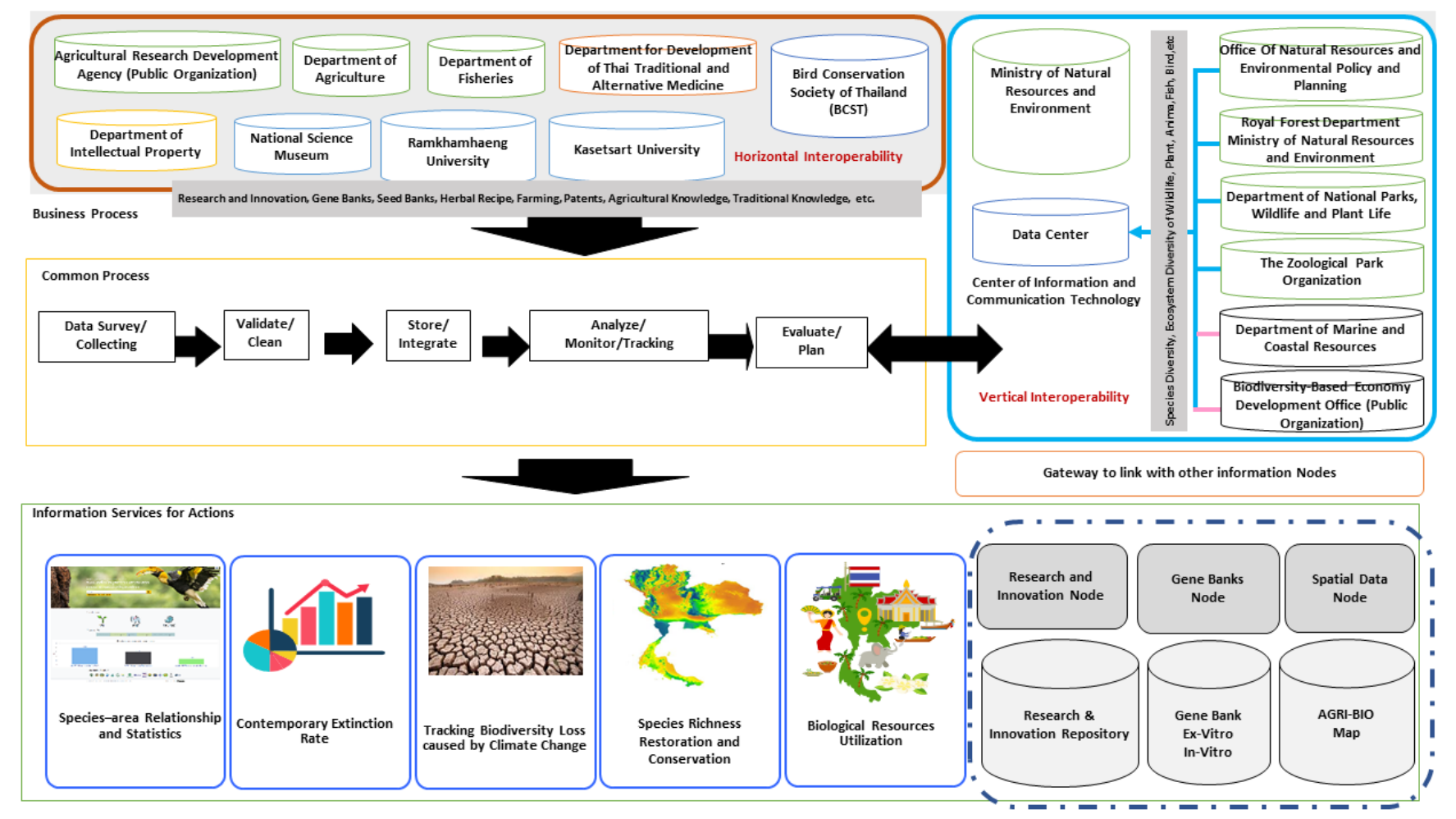

Fig. 3. An Overview of Current TH-BIF Platform Design

data set, we construct a deep CNN model using Mask-r CNN technique which is one of the most accurate and widely-used approach. The constructed model produces accurate disease durian trees detection with around 76\% of mAP @ IOU 0.5. Fig. 2 shows the output of identifying which durian trees got the disease problem.

Main advantages of drones are 1) ability to cover a large area in the farm 2) acquisition of good quality videos/images 3) reasonable cost. However, drones' flying time is short (1015 minutes) and they easily fall-down if hit by obstacles. Thus, bird-eye view images of the farm are captured by drones that fly at high attitude. Moreover, to produce more accurate disease durian detection, a cascade deep CNN approach will be applied. In conclusion, better quality of images can be acquired by controlling the way of flying drones e.g. height from ground, speed and flying routes instead of manual flying.

3) A Development of Thailand Biodiversity Information Facility Platform (TH-BIF): The TH-BIF [3] is an on-going project that has been developed since 2018. It has been hosted and sponsored by the Office of Natural Resource and Environment Planning and Policy, Ministry of Natural Resources and Environment. The main goal of TH-BIF is to build up a platform for information sharing ecosystem across government agencies among stakeholders who own data related to biodiversity (see Fig. 3). It also facilitates the use of tools for data migration, integration, and provides information services for biodiversity conservation, restoration and utilization.
It is well-known [9] that biodiversity is the source of the diversity of plants and animals used in agriculture for food, nutrition and medicinal purposes. This diversity within species partly results from the selection by human based on specific traits and DNA, to meet environmental and other conditions, such as the ability to tolerate drought or frost. However, at present there is no existing platform for data integration between the two domains biodiversity and agriculture. Accordingly, this work contributes to build a platform for providing farmers and agricultural producers with data and knowledge services, in order to increase the agricultural productivity while safeguarding the biodiversity losses.

4) Lessons Learned from the Past and Present: What we learnt from the above projects is first that the success factors of the information sharing projects strongly depend on cohesive working networks and multi-sectors engagement, including the government agencies that own the data. We also found that effective communication strategy is necessary to better promote understanding and achieve our aims and objectives in open data and data sharing policy. Additionally, we also need an Enterprise Architecture (EA) as a blue print for proactively and holistically leading enterprise responses to disruptive forces by identifying and analyzing the execution of change toward desired business vision and outcomes in agricultural biodiversity management.

Secondly, Data and Knowledge Services Offering and digital skill training are necessary for the self advancement of rural community, especially the smallholder farmers, in access- 


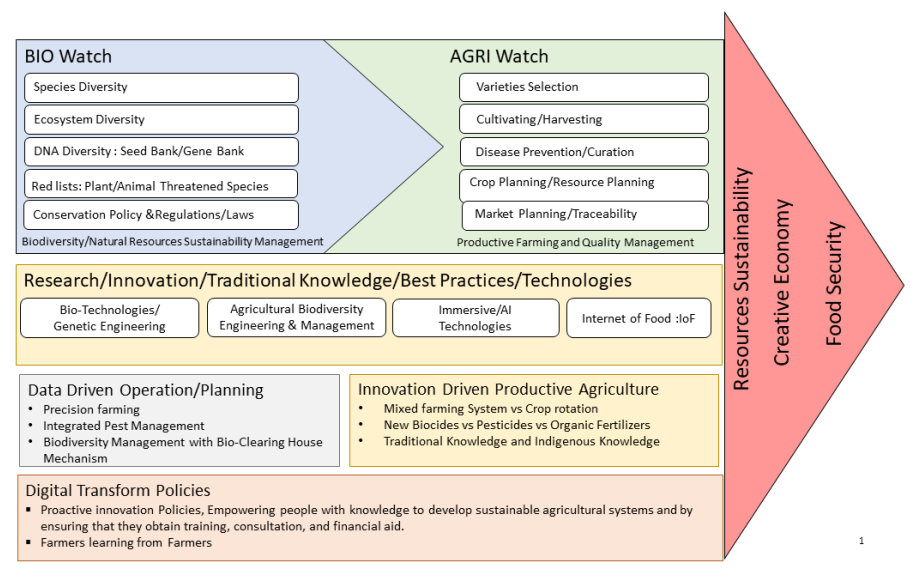

Fig. 4. Concept Merging Model for considering Biodiversity as a Vital element of Sustainable Agriculture

ing technological advances. In conclusion, truly sustainable development in sustainable food system must empower the small family farmers with knowledge, realizing the benefits from data access and use, and minimizing their risks. Accordingly, there exists a strong need to engage more in local $\mathrm{R} \& \mathrm{D} /$ Traditional knowledge, for example, while setting priorities in research fields appropriate to their specific resources and contexts.

Finally, it is also necessary to set up regulatory frameworks in performing continuous input for getting up-to-date data from the data owners, and for providing other best practices information to enhance both productivity and biodiversity loss management.

Based on the above learnt lessons, the fifteen departments and organization are engaged to design and define the data sets necessary for manage biological resources management. Fig. 3 shows the design of common business for data collecting, integrating and analyzing for providing information services such as tracking biodiversity losses and their causes relationships. The data will be integrated across government agencies both in vertical inter-operability level, i.e., among departments under Ministry of Natural Resources and Environment, and horizontal inter-operability levels, i.e., among departments which cover the domain of agriculture, domain of biodiversity utilization, domain of research and innovation and patents from Ministry of Agricultural and Cooperatives, Ministry of Public Health, Ministry of High Education, Science, Research and Innovation, and Ministry of Commerce, respectively.

In Fig. 3, the data objects in the dashed frame at the lower right corner will be included for development in the next year plan.

The TH-BIF platform also provides tools for data migration, merging and integration. In order to achieve the goals of sustainable and productive agriculture and be able to harvest best practices for performing continuous input for up-to-date data from government agencies, we start with BIO-AGRIWATCH concept and extend it to integrate research and innovation components. As shown in Fig. 4, based on merging concepts in biodiversity, agriculture and research \& innovation, data-driven operation \& planning, innovation driven problem solving in agriculture would be holistically leading enterprise responses for considering biodiversity as an integral part of agriculture and as a vital element of sustainable agriculture.

A concept behind BIO-AGRI-WATCH has been aligned with 20 years Thailand's National Strategy (2018-2037) that was to contribute to more meaningful citizen-centric services. With digital and data-knowledge driven agriculture practices, smallholder farmers will become smart data managers and users for agricultural biodiversity management, and be able to create new opportunities towards both bio-economy and food security which is one of the UN SDGs (Sustainable Development Goals) [7]. As can be seen in Fig. 4, our proposed model includes Digital Transformation Policy as one of the driver mechanisms for data sharing.

\section{Conserving Biodiversity for Sustainable AGRICULTURE}

As mentioned earlier, precision farming relies upon: (1) intensive sensing of environmental conditions in the crop, (2) extensive data handling and processing, (3) use of decision support systems, (4) control of farm operations in the field and (5) conserving and restoring the biodiversity. The needed information will be collected based on the development of new tools in information technology, such as sensors, drones, robots, virtual and augmented reality, and geographic information systems. Fig. 5 shows the data needed from surveying, several devices, several websites and several databases.

The following challenges have to be addressed in order to obtain the decision support systems for precise agriculture, such as for crop and disease management, precision treatments, while conserving and planning the strategies for biodiversity management:

- How to integrate data coming from different sources?

- How to design and implement the algorithms necessary for analysing large amounts of data?

- How to control the quality of data before it is used in algorithms? 


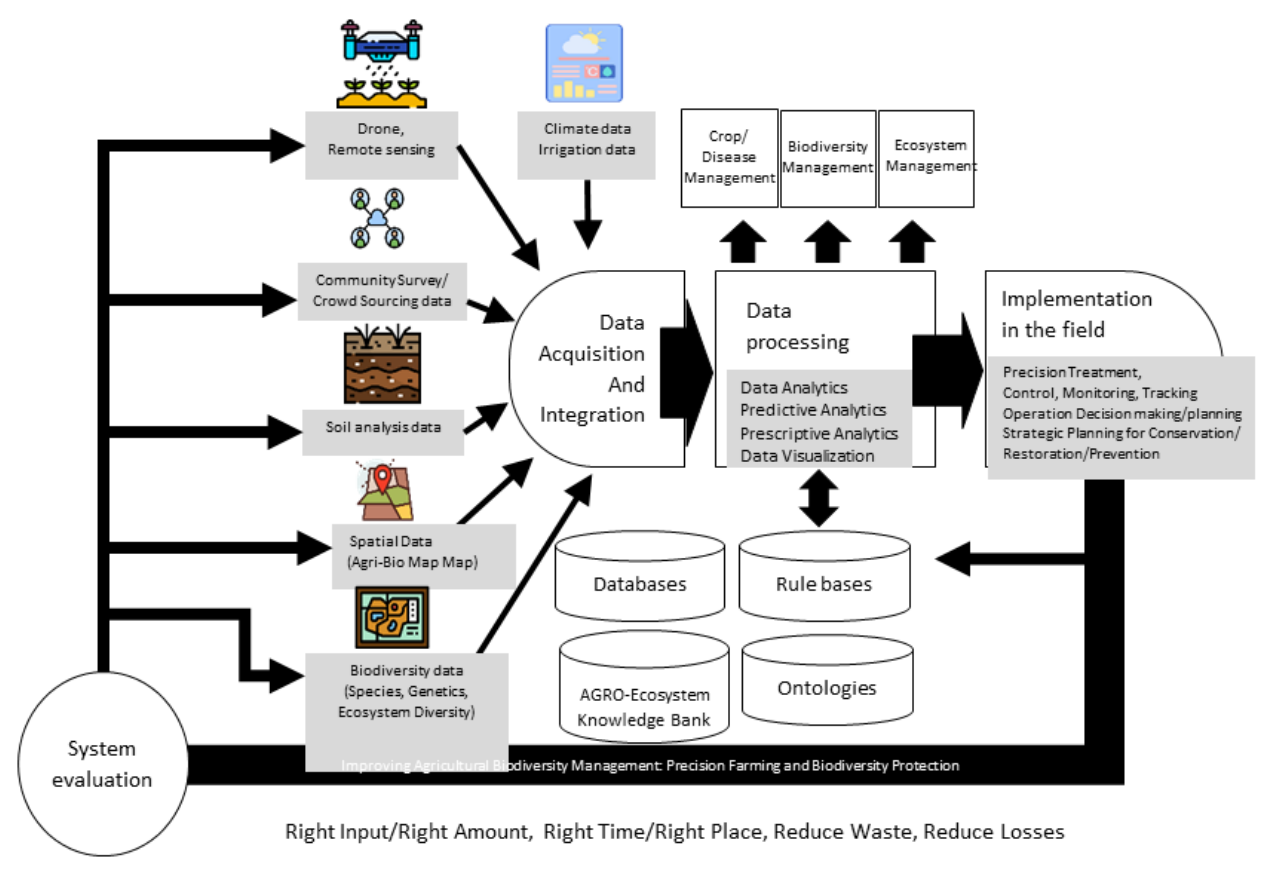

Fig. 5. The Sources of Data needed for Agricultural Biodiversity Management

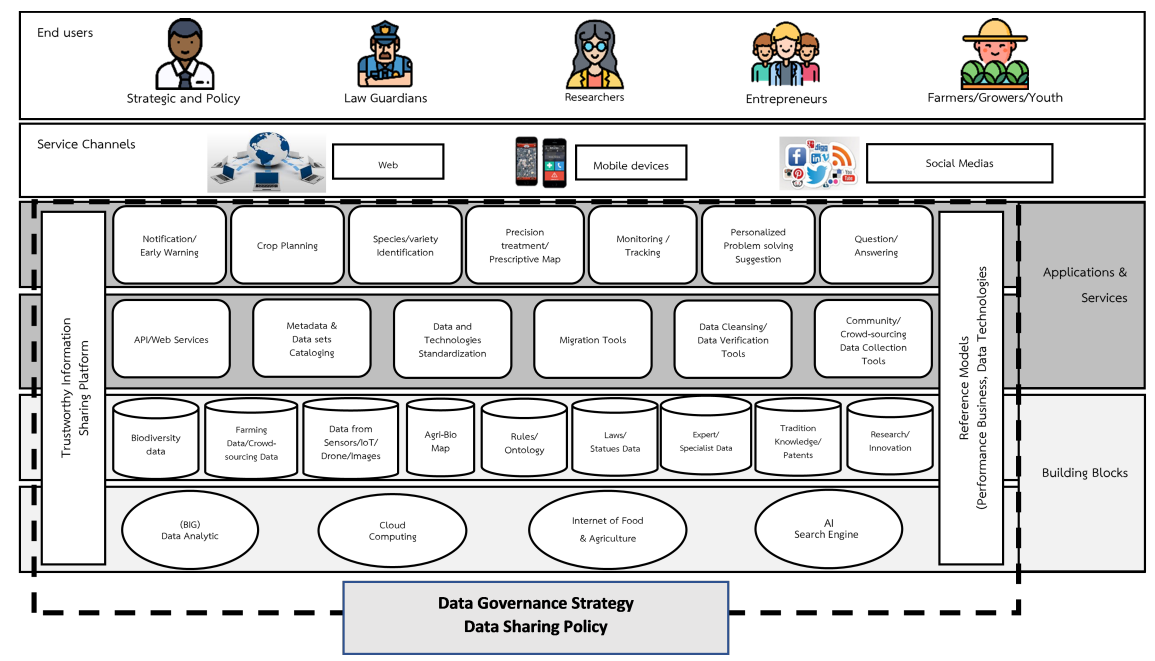

Fig. 6. The layers of Architectures and Service Offering

- How to build a decision support system based on the above mentioned items?

In this article, we focus on two related key-challenges: how to make data inter-operable when re-engineering the existing information system and how to build a trustworthy platform for data collection, integration and sharing.

\section{A. A Proposed Solution Platform}

Fig. 6 shows the layers of an enterprise architecture with service offering to each target end-user, i.e., Strategic and Policy makers, Law guardians, Researchers, Farmers, and Entrepreneurs.
As shown in Fig. 6, various services are designed and developed with the purpose of supporting user-experience based services for each target end-user, e.g., crop planning service and disease warning for farmers, genetic resources planning for researchers, and information supporting coherent actions for the conservation, sustainable use, resource optimization planning and restoration of biodiversity across agricultural sectors.

Indeed, if we collect data over long periods of time, and if we integrate, analyze and update these data either continuously or in real time, we could find hidden patterns and indicators that help enhancing agriculture practices and sustainability, for example helping farmers determine what happens, why 


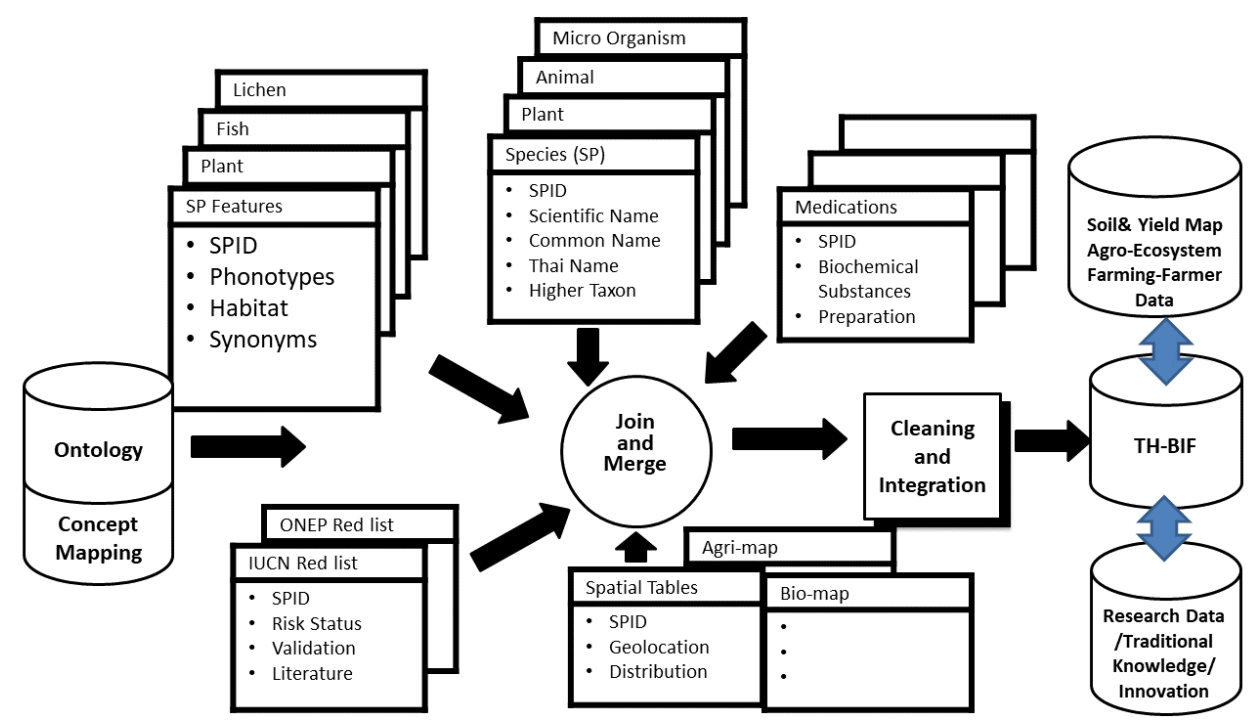

Fig. 7. An Example of Data sets and Syntax Inter-operability for Data Integration

it happens, when to rotate crops and what should be done.

\section{B. A Proposed Inter-operability Framework}

To bring big data of high quality to the platform, interoperability of information sharing and data access play a critical role in improving the agricultural biodiversity management and ecosystem service outcomes, in order to lower data collection costs, and improve the user experience of operating, decision making and planning.

A proposed inter-operability framework consists of:

1) Define Object abstraction inter-operability, which consists of vocabularies for communication, composite data object abstraction and metadata description for data reference model;

2) Consensus with the Community of Interest in data sharing for Syntactical Inter-operability by defining Data Formats and Data Model;

3) Define Semantic Interoperability which consists of a Semantic Schema, an Ontologies and Semantic Annotations.

We also need the functions for object interoperation, syntactic mediation and semantic mediation as shown in Fig. 7.

Using ontologies can improve data integration across three domains: agriculture, biodiversity and laws. Moreover, we can use the ontology for providing information service connectivity with suggestion recommendation to the end users, as shown in Fig. 8.

In conclusion, we need three levels of inter-operability. The resulting Syntax-Semantic-Organizational Inter-operability model aims to provide a candidate best practice for engineering data and knowledge integration through a community-shared and reusable Data Reference Model. Regarding organizational inter-operability, a process agreement is needed, to allow the system participate in multi-organizational business processes.
Semantic Inter-operability focuses on Meaning Exchange which means that the system can exchange meaningful information.

Additionally, Technical Inter-operability, including syntactic inter-operability which is a prerequisite for semantic interoperability, will allow for packaging and data exchange.

\section{IMPLEMENTATION AND DATA GOVERNANCE MECHANISM}

For the success of the continuity of data integration development, it is essential to identify potential benefits such as better operational efficiency, better decision making and strategic planning and better customer services. Fig. 8 shows the integrated data services through a single window. The output was designed according to the experience of researchers and strategic planners.

In order to be tangible, these benefits need to be measurable for tracking the progress of a program/project and also finding ways to improve it in the future. This work aims to address this issue and also to set up a Data Governance Strategy (see Fig. 9) with the dedicated governance team for Data Sharing and Data Quality management. The team consists of the Chief Data Governance Officer, data owners, data stewards, data custodians and specialists in the specific areas such as data standardization, and big data analytics.

To implement and harvest best practices in Agricultural Biodiversity Project aiding in data governance implementation, the following tasks must be completed:

- Define the vision and scope of the project for 5 years (2017-2021);

- Design an Information Sharing Ecosystem Architecture, including defining the data reference model and metadata for the data sources;

- Develop a platform, processes and tools for data standardization, data integration and/or migration tools for new data; 


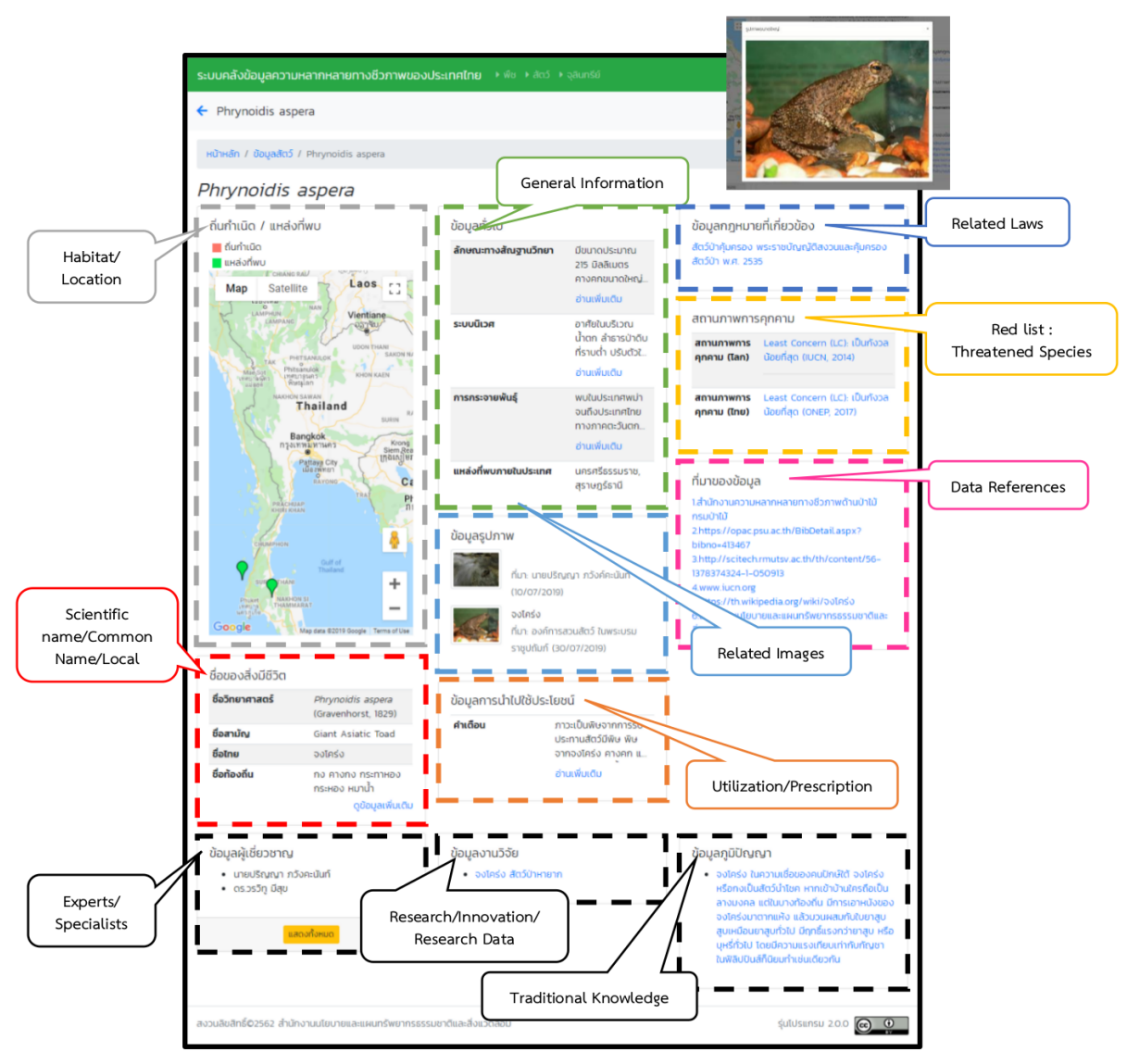

Fig. 8. Single window based Information Services: BIO WATCH.

- Develop data analysis tools for a tangible demonstration of the benefits to be gained from data sharing and integration;

- Train and improve data literacy for all staff across organizations that participate in the project;

- Define the Data Governance Strategy and setting dedicated team for evaluating the suitability of new data sources, managing and creating metadata, doing research and integrating the new data, monitoring and enforcing compliance with data sharing policy and open data policy.

The resulting Data Governance Implementation across government agencies, by using BIO-AGRI-WATCH as a case study, has significant consequences ranging from communication and engagement with stakeholders and dedicated teams for increasing digital trust in sharing their data.

\section{CONCLuSion ANd Future Work}

This work is devoted to innovation needed to increase productivity and sustainability in food, biodiversity and agriculture. This work shows that innovative agricultural systems should be improved so as to make them more collaborative and responsive to needs through data sharing and integrating. To cope with these challenges, the following topics have been identified as relevant: digital remote sensing, geographic information systems, crop and soil health monitoring, and farm management Data Governance Implementation is also the key to such improvements.We also found that success strongly depends on cohesive working networks and multisector engagement, including government agencies.

Since the influence factors for the success of interoperability are legal, political, managerial, economic, social and cultural, the next step is dedicated to innovation in agriculture and food systems, in order to maintain the productivity growth in a sustainable fashion. The topics to be addressed in this respect include data-driven strategies, the impact of biotechnological and digital technologies, effective policies, and strengthened networks.

\section{Acknowledgements}

The authors wish to thank the Agriculture Research Development Agency (ARDA) and the Office of Natural Resources and Environmental Planning and Policy for supporting this work. And special thanks go to Franco-Thai Cooperation Program in Higher Education and Research (Franco-Thai Mobility Program / PHC SIAM 2018-2019) for supporting research between France and Thailand. 


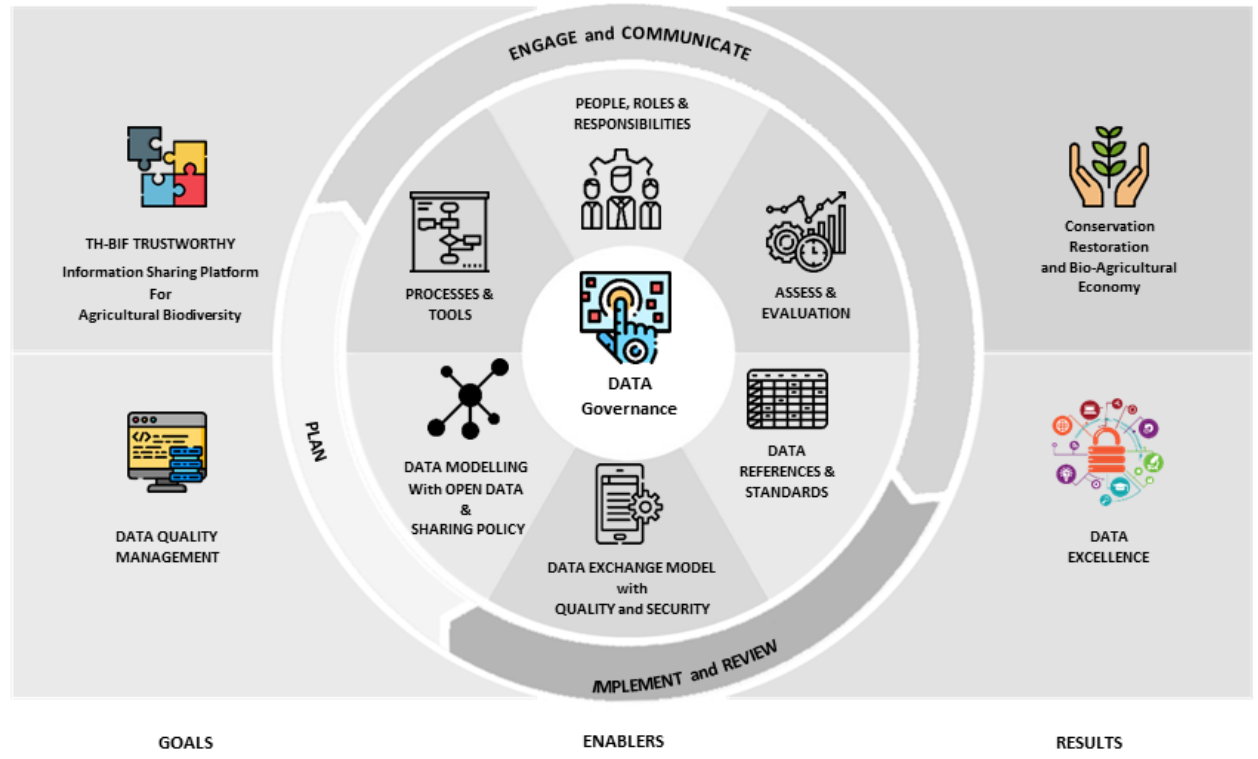

Fig. 9. Data Governance as an enabler for Data Quality Management

\section{REFERENCES}

[1] Kawtrakul, A.: A development of rice watch system for strategic planning in rice economic and marketing phase $2\left(2^{\text {nd }}\right.$ year). Tech. rep., U-Know Center, Kasetsart University (2016)

[2] Kawtrakul, A.: Biodiversity data center development project final report. Tech. rep., Kasetsart University, Office of Natural Resources and Environmental Policy and Planning (2018)

[3] Kawtrakul, A.: Biodiversity data center performance enhancing project final report. Tech. rep., Kasetsart University, Office of Natural Resources and Environmental Policy and Planning (2019)

[4] Kawtrakul, A., Amorntarant, R., Chanlekha, H.: Development of an expert system for personalized crop planning. In: Proceedings of the 7th International Conference on Management of Computational and Collective intElligence in Digital EcoSystems. pp. 250-257. MEDES '15, ACM, New York, NY, USA (2015). https://doi.org/10.1145/2857218.2857272, http://doi.acm.org/10.1145/2857218.2857272

[5] Kawtrakul, A., Spyratos, N.: Soft wheel: An information system for optimizing rice production. In: Proceedings of the 8th International Conference on Management of Digital EcoSystems. pp. 43-46. MEDES, ACM, New York, NY, USA (2016). https://doi.org/10.1145/3012071.3012073, http://doi.acm.org/10.1145/3012071.3012073

[6] Kawtrakul, A., Tippayarak, P., Andres, F., Ujjin, S.: Personal warning service for pest management using a crop calendar and bus model. In: Proceedings of the 7th International Conference on Management of Computational and Collective intElligence in Digital EcoSystems. pp. 242-249. MEDES '15, ACM, New York, NY, USA (2015). https://doi.org/10.1145/2857218.2857271, http://doi.acm.org/10.1145/2857218.2857271

[7] Maru, A., Berne, D., Beer, J.D., Ballantyne, P.G., Pesce, V., Kalyesubula, S., Fourie, N., Addison, C., Collett, A., Chavez, J.: Digital and datadriven agriculture: Harnessing the power of data for smallholders. Global Forum on Agricultural Research and Innovation (2018)

[8] Phwanwilai, R., Kangkachit, T.: Automated plant disease detection using drones and deep learning. In: The national Conference on Computing and Information Technology (NCCIT). pp. 189-194. Bangkok (2019)

[9] Secretariat CBD: Agriculture safeguarding biodiversity and securing food for the world. Tech. rep. (2008), [Retrieved September 15, 2019]

[10] Toledo, Á., Burlingame, B.: Biodiversity and nutrition: A common path toward global food security and sustainable development. Journal of food composition and analysis 19(6-7), 477-483 (2006)

[11] Zhang, N., Wang, M., Wang, N.: Precision agriculture-a worldwide overview. Computers and Electronics in Agriculture 36(2), 113 - 132 (2002). https://doi.org/https://doi.org/10.1016/S0168-1699(02)00096-0, http://www.sciencedirect.com/science/article/pii/ s0168169902000960 